\title{
The Future of Agricultural Jobs in View of Robotization
}

\author{
Vasso Marinoudi ${ }^{1,2}{ }^{\mathbb{D}}$, Maria Lampridi ${ }^{3} \mathbb{D}$, Dimitrios Kateris ${ }^{3} \mathbb{D}$, Simon Pearson ${ }^{1} \mathbb{D}$, Claus Grøn Sørensen ${ }^{4}$ \\ and Dionysis Bochtis ${ }^{3, *(1)}$
}

1 Lincoln Institute for Agri-Food Technology (LIAT), University of Lincoln, Lincoln LN6 7TS, UK; vm352@efb.gr (V.M.); SPearson@lincoln.ac.uk (S.P.)

2 Engineers for Business S.A. (EfB), Doiranis 17, GR 54639 Thessaloniki, Greece

3 Institute for Bio-Economy and Agri-Technology (IBO), Centre of Research and Technology-Hellas (CERTH), GR 57001 Thessaloniki, Greece; m.lampridi@certh.gr (M.L.); d.kateris@certh.gr (D.K.)

4 Department of Electrical and Computer Engineering, Aarhus University, DK-8000 Aarhus, Denmark; claus.soerensen@ece.au.dk

* Correspondence: d.bochtis@certh.gr

check for updates

Citation: Marinoudi, V.; Lampridi, M.; Kateris, D.; Pearson, S.; Sørensen, C.G.; Bochtis, D. The Future of Agricultural Jobs in View of Robotization. Sustainability 2021, 13, 12109. https://doi.org/10.3390/ su132112109

Academic Editors: Michael

S. Carolan, Charisios Achillas and Dimitrios Aidonis

Received: 26 September 2021

Accepted: 29 October 2021

Published: 2 November 2021

Publisher's Note: MDPI stays neutral with regard to jurisdictional claims in published maps and institutional affiliations.

Copyright: (C) 2021 by the authors Licensee MDPI, Basel, Switzerland. This article is an open access article distributed under the terms and conditions of the Creative Commons Attribution (CC BY) license (https:/ / creativecommons.org/licenses/by/ $4.0 /)$.

\begin{abstract}
Robotics and computerization have drastically changed the agricultural production sector and thus moved it into a new automation era. Robots have historically been used for carrying out routine tasks that require physical strength, accuracy, and repeatability, whereas humans are used to engage with more value-added tasks that need reasoning and decision-making skills. On the other hand, robots are also increasingly exploited in several non-routine tasks that require cognitive skills. This technological evolution will create a fundamental and an unavoidable transformation of the agricultural occupations landscape with a high social and economic impact in terms of jobs creation and jobs destruction. To that effect, the aim of the present work is two-fold: (a) to map agricultural occupations in terms of their cognitive/manual and routine/non-routine characteristics and (b) to assess the susceptibility of each agricultural occupation to robotization. Seventeen (17) agricultural occupations were reviewed in relation to the characteristics of each individual task they entail and mapped onto a two-dimensional space representing the manual versus cognitive nature and the routine versus non-routine nature of an occupation. Subsequently, the potential for robotization was investigated, again concerning each task individually, and resulted in a weighted average potential adoption rate for each one of the agricultural occupations. It can be concluded that most of the occupations entail manual tasks that need to be performed in a standardised manner. Considering also that almost $81 \%$ of the agricultural work force is involved with these activities, it turns out that there is strong evidence for possible robotization of $70 \%$ of the agricultural domain, which, in turn, could affect $56 \%$ of the total annual budget dedicated to agricultural occupations. The presented work silhouettes the expected transformation of occupational landscape in agricultural production as an effort for a subsequent identification of social threats in terms of unemployment and job and wages polarization, among others, but also of opportunities in terms of emerged skills and training requirements for a social sustainable development of agricultural domain.
\end{abstract}

Keywords: agricultural robots; tasks automatization; occupations classification; human-robot substitution; human-robot complementarity

\section{Introduction}

Unlike the industrial sector, which is a relatively steady environment including generally well-defined and repetitive tasks to be carried out, the agricultural production sector is a dynamic ecosystem characterized by high unpredictability and variability [1]. Agriculture deals with sensitive "live" produce, which requires gentle handling and can be affected by environmental conditions [2]. Furthermore, for example, arable production it is highly seasonal since a considerable amount of time intercedes from sowing to harvesting. As a consequence, field operations are usually restricted by workability constraints that can be 
particularly critical with respect to the quality of the final product [3]. These operational features in agricultural production create specific workforce requirements in terms of abilities, range of expertise, and timely availability and supply.

With the intention of increasing the productivity as well as decreasing production costs and the drudgery of agricultural manual operations [4], robots were introduced in an effort to increase reliability, efficiency, and resilience of crop production systems [5]. The advent of robots in conjunction with technological advancements in information technologies has yielded radical solutions to a plethora of problems that farmers face, including the ability to work under hazardous conditions by demonstrating strength and repeatable accuracy. Illustrative examples of field operations performed by agricultural robots are harvesting [6,7], spraying [8,9], seeding [10,11], and weeding [12,13]. Several review studies exist in literature summarizing the recent advancement in agricultural robotics such as $[1,5,14-16]$.

The above-mentioned robotics applications in agriculture regard tasks requiring physical strength and performed in a repetitive manner, while no considerable cognitive skills are required for the right execution of them. As stressed by Autor et al. (2003), autonomous systems turn out to be more easily replaceable for human labor for routine compared to non-routine activities [17]. Since the goal of automation is mainly to delegate the repetitive and tedious tasks to a robot or computer, routine tasks also requiring cognitive skills can be automatized. This is a rather more challenging situation as compared with the corresponding manual tasks. The reason for this is because robots or computers should be able to mimic human skills and repeat their activities once rules are strictly defined by humans. As far as the tasks that need to be performed in a non-standardised way and by exploiting cognitive skills are concerned, they are very difficult to be automatized Robots are still not able to equal the depth of human perception by virtue of a plethora of small variations existing within even a single task. Nevertheless, computers are getting better at carrying out non-routine tasks that necessitate cognitive abilities because of their capacity to rapidly evaluate big data sets. Examples include AI implementation in yield prediction [18], crop water status [19], disease detection [20], and weed detection [21], among numerous applications in agriculture. Computers are more and more learning to perceive features' interconnected hierarchies in the way the human brains do.

Interestingly, by taking advantage of both the distinctive cognitional human skills and robots' accuracy, synergetic ecosystems can be composed, which, through their efficient interaction, have shown a great potential to overcome the limitations occurring because of the complex and unpredictable agricultural environment [22]. Indicative successful applications of such kind of collaborative systems are presented, for example, in [23-25].

Considering the above analysis, it can be inferred that agricultural occupations are under an extensive conversion. The once arduous manual and routine operations that demand physical strength, such as digging, lifting, carrying, and pushing, tend to be automated and robotized. In addition, the ever-increasingly incorporation of modern technologies has generated cognitive machines that could also carry out non-routine tasks that require cognitive skills, such as perception, memory, reasoning, as well as rapid decision making and acting [26,27]. Consequently, there seems to be on one hand a gradual substitution of humans by robots, while at the same time, on the other hand, new approaches evolve towards complementarity between human and robots. As it has been concluded by the recent study of Marinoudi et al. (2019), there is a need for a formal decomposition of the various tasks executed during agricultural operations in the light of the upcoming automatization (robotization and computerization) [28]. Towards that direction, each individual occupation should be characterized as it can be subject or not to automation and in what level. To that effect, the aim of the present study is two-fold:

- To map agricultural occupations in terms of their cognitive/manual and routine/nonroutine nature and

- To assess the susceptibility of agricultural occupations to the adoption of robotization. 
The remainder of the paper is arranged as follows: in Section 2, the applied occupation classification system is analyzed with emphasis put on agricultural sector along with the methodology regarding the indexing of occupations in terms of their cognitive/manual and routine/non-routine levels as well as its level of susceptibility to robotization. Section 3 follows, where the main results are presented, including the mapping of the various agricultural occupations on the cognitive/manual and routine/non-routine space and their rate of the susceptibility to robotization as well as the visual connection between this potential adoption rate and the nature of each occupation. The same Section provides, as a discussion, the reflection of these results on agricultural occupations landscape in terms of the short-/mid-term effects of robotization on agricultural workforce. Finally, conclusions are drawn in Section 4 by highlighting future challenges existing in agriculture.

\section{Materials and Methods}

\subsection{Classification of Agricultural Occupations}

The implemented occupational classification system, namely the Standard Occupational Classification (SOC) system, was created by the U.S. government as a statistical standard system for the categorization of workers into the relevant occupational categories. In brief, the utilized 2018 edition of the SOC classifies the total labor force in 867 distinct occupations. These occupations are classified in 459 broadly defined occupations that are further categorized in 98 minor groups and, finally, in 23 major groups [29]. For example, the occupation of "Farmworkers and Laborers, Crop, Nursery, and Greenhouse" (Code: 45-2092) belongs to the broadly defined occupation of "Miscellaneous Agricultural Workers" (Code: 45-2090), which belongs to the minor group of "Agricultural workers" (Code: 45-2000), which, in turn, belongs to the major group of "Farming, Fishing, and Forestry Occupations" (Code: 45-0000). The SOC system of the U.S. Bureau of Labor Statistics is expanded from a 6-digit to an 8-digits scheme resulting in the O*NET classification system, which adds the classification level of specific jobs [30]. The occupations are described and classified based on a series of attributes, criteria, and requirements. These include the tasks that are performed; the technological skills and other skills that are required; the knowledge, interests, and abilities of the worker; the work activities and context; and the job zone that the occupation belongs to. For the purposes of the presented work, the detailed 8-digits $\mathrm{O}^{*} \mathrm{NET}$ occupational classification system was used similarly to recent studies such as [31,32].

In total, 17 occupations associated with agriculture were considered in the present study. The criterion for the selection was the direct involvement of the occupation's tasks in the physical processes of crop and livestock production. To that effect, occupations related to agri-products trading and labor and/or producers training were not included in the selected occupations, and occupations dealing with forestry and aquaculture activities were also not included in the present analysis. Hence, only occupations directly related to crop and livestock production were investigated. The reviewed occupations are listed in Table 1 together with the $\mathrm{O}^{*} \mathrm{NET} 8$-digit code. Each occupation involves several tasks that are described by O*NET. For example, for the "Farmworkers and Laborers, Crop, Nursery, and Greenhouse" (O*NET code: 45-2092.00), 30 tasks are described. Additionally, for example, the tasks of this occupation include: harvest plants and transplant or pot and label them; set up and operate irrigation equipment; repair and maintain farm vehicles, implements, and mechanical equipment; harvest fruits and vegetables by hand; and identify plants, pests, and weeds to determine the selection and application of pesticides and fertilizers, among 30 in total. 
Table 1. The 17 reviewed occupations along with the O*NET 8-digit code and the number of tasks they entail.

\begin{tabular}{|c|c|c|c|}
\hline $\mathbf{a} / \mathbf{n}$ & Occupation & O*NET Code & $\begin{array}{c}\text { Number of Tasks } \\
\text { Described by O*NET }\end{array}$ \\
\hline 1 & Nursery and Greenhouse Managers & $11-9013.01$ & 20 \\
\hline 2 & Farm and Ranch Managers & $11-9013.02$ & 26 \\
\hline 3 & Farm Labor Contractors & $13-1074.00$ & 8 \\
\hline 4 & Agricultural Engineers & $17-2021.00$ & 13 \\
\hline 5 & Animal Scientists & $19-1011.00$ & 9 \\
\hline 6 & Soil and Plant Scientists & $19-1013.00$ & 20 \\
\hline 7 & Agricultural Technicians & $19-4011.01$ & 25 \\
\hline 8 & Food Science Technicians & $19-4011.02$ & 15 \\
\hline 9 & $\begin{array}{l}\text { First-Line Supervisors of Agricultural } \\
\text { Crop and Horticultural Workers }\end{array}$ & $45-1011.07$ & 24 \\
\hline 10 & $\begin{array}{l}\text { First-Line Supervisors of Animal } \\
\text { Husbandry and Animal Care Workers }\end{array}$ & $45-1011.08$ & 18 \\
\hline 11 & Agricultural Inspectors & $45-2011.00$ & 22 \\
\hline 12 & $\begin{array}{c}\text { Graders and Sorters, Agricultural } \\
\text { Products }\end{array}$ & $45-2041.00$ & 5 \\
\hline 13 & Agricultural Equipment Operators & $45-2091.00$ & 17 \\
\hline 14 & Nursery Workers & $45-2092.01$ & 21 \\
\hline 15 & Farmworkers and Laborers, Crop & $45-2092.02$ & 14 \\
\hline 16 & Farmworkers, Farm, Ranch & $45-2093.00$ & 22 \\
\hline 17 & $\begin{array}{l}\text { Farm Equipment Mechanics and Service } \\
\text { Technicians }\end{array}$ & $49-3041.00$ & 13 \\
\hline
\end{tabular}

\subsection{Occupation Type Mapping}

Firstly, the indexing of the agricultural occupations in relation to their cognitive/manual and routine/non-routine levels was performed. To meet this objective, for each individual task of an occupation, four coefficients characterizing the nature of the occupation as (a) cognitive routine, (b) cognitive non-routine, (c) manual routine, and (d) manual non-routine were introduced.

Let $O=\{1, \ldots, 17\}$ denote the set of indices of the 17 selected agricultural occupations and $T_{i}=\{1,2, \ldots\}$ denote the set of indices regarding the defined tasks of an occupation, with $i \in O$. For each task of an occupation, an importance weight, $\bar{w}_{i, j}, i \in O, j \in T$, is allocated. The importance weight is the average outcome of a series of participatory interventions with professionals in agricultural occupations. The importance of the task within the occupation is rated by each interviewed professional based on the following scale:

- Not important: Score 1

- Slightly important: Score 2

- Important: Score 3

- Very important: Score 4

- Strongly important: Score 5

Afterwards, the normalized weight of the importance of a task can be given by:

$$
\hat{w}_{i, j}=\frac{\bar{w}_{i, j}}{\sum_{j \in T} \bar{w}_{i, j}}, i \in O, j \in T
$$

After rating the "importance" of each individual task of the occupation, the process of indexing the nature of each task takes place. For each task, a set of four coefficients is allocated, namely $a_{i, j}^{k}, i \in O, j \in T$, where $k \in K=\{C R, C n R, M R, M n R\}$ determines the cognitive routine $(C R)$, cognitive non-routine $(C n R)$, manual routine $(M R)$, and manual non-routine $(M n R)$ coefficient, respectively. Finally, for each task, the assessors provided values from the set $[0,0.25,0.5,0.75,1]$ to scale the contribution of the cognitive routine, cognitive non-routine, manual routine, and manual non-routine attributes to the execution 
of the task, under the condition that the summation of all values within a task is equal to 1 $\left(\sum_{k \in K} a_{i, j}^{k}=1, \forall i \in O, j \in T\right)$.

The cognitive/manual balance (y-coordinate in the corresponding graph) of an occupation is given by:

$$
l_{i}^{C-M}=\sum_{j \in T}\left[\hat{w}_{i, j}\left(a_{i, j}^{C R}+a_{i, j}^{C n R}-a_{i, j}^{M R}-a_{i, j}^{M n R}\right)\right] \rightarrow[-1,1]
$$

while the routine/non-routine balance ( $\mathrm{x}$-coordinate in the corresponding graph) is given by:

$$
l_{i}^{R-n R}=\sum_{j \in T}\left[\hat{w}_{i, j}\left(a_{i, j}^{C n R}+a_{i, j}^{M n R}-a_{i, j}^{C R}-a_{i, j}^{M R}\right)\right] \rightarrow[-1,1]
$$

The above indices can be considered as coordinates for mapping a particular operation in the cognitive/manual and routine/non-routine 2D-space where the routine against nonroutine nature correspond to the horizontal dimension, while manual versus cognitive nature correspond to the vertical dimension Figure 1. A schematic representation of the applied methodology described in this section can be shown in Figure 2.

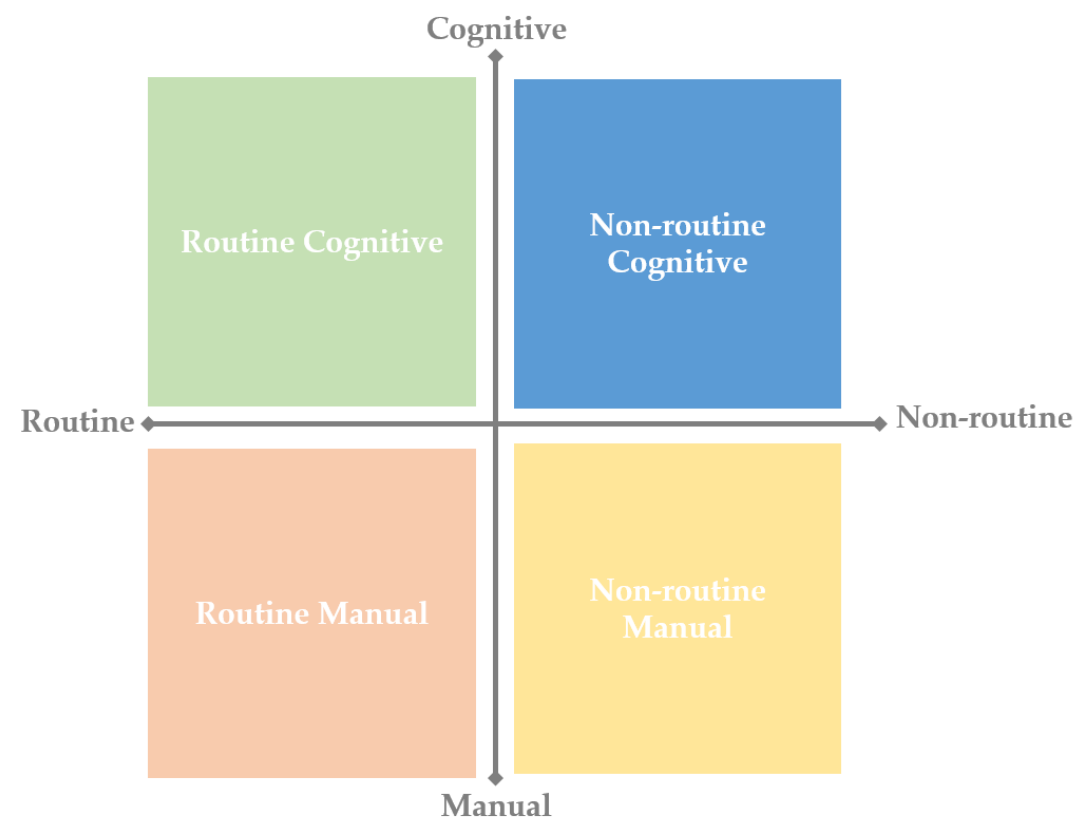

Figure 1. The virtual cognitive/manual and routine/non-routine space implemented for the characterization of occupations (adapted from [28]; Note that the quadrants colors are in consistency with colors in subsequent Figures 4 and 6).

The values of the coefficients for each task were determined by the authors of this paper, who independently evaluated each task by exploiting their own experience in conjunction with an experienced group of professionals in the agricultural sector, including first-line supervisors of animal and crop production, farm managers, and several agricultural workers in nursery, horticulture, and livestock production. A consensus meeting of the reviewers was held to resolve any difference of opinion and decide the final scores. 


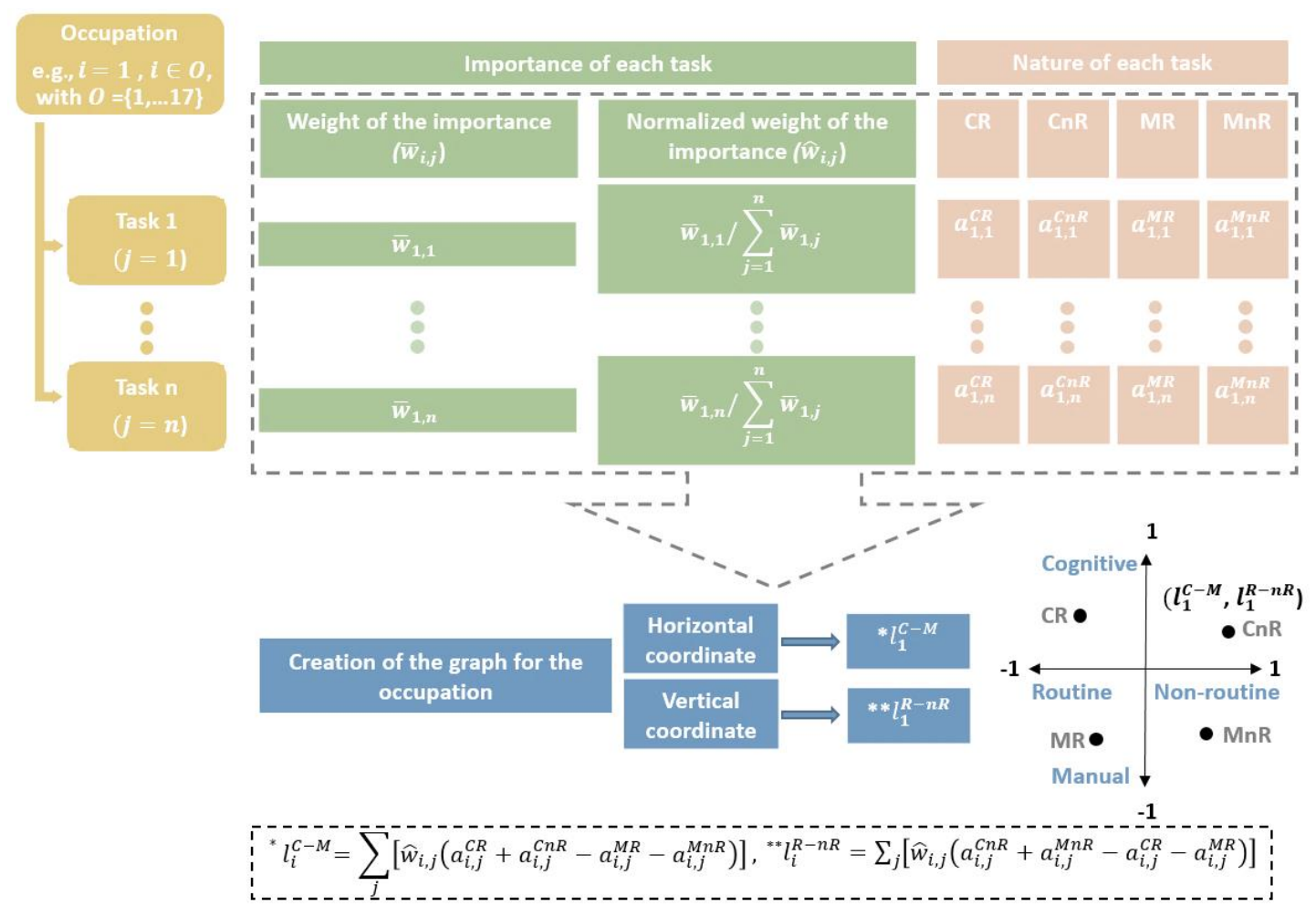

Figure 2. Outline of the applied methodology for the derivation of the graph characterizing the level of cognitive/manual and routine/non-routine; the abbreviations $C R, C n R, M R$, and $M n R$ refer to possible combinations, namely the Cognitive Routine, Cognitive non-Routine, Manual Routine, and Manual non-Routine, respectively.

\subsection{Occupation Susceptibility to Robotization}

The second aspect of this study was to examine the potential of each task comprising an occupation to be robotized. The basis for characterizing a specific task of an occupation in terms of its adoptability for automation was, firstly, if there is already a developed technology that can replace the human worker from the task and, secondly, if not, the technology readiness level (TRL) of under-development technologies that could replace (fully or partially) the worker in the execution of the task. The minimum accepted TRL for such a technology was assessed as the level 3, described as "Level 3: proof-of-concept demonstrated analytically and/or experimentally". This means that for the technology under consideration, the feasibility has been demonstrated, and there is a practical potential from developing this technology further.

Accordingly, the team of technology experts rated each task based on the following scale:

- Score 0: There is not a technology at TRL3 or higher demonstrated, or there is not any reasonable indication that the particular task can be computerized-robotized in the short- or mid-term future.

- Score 0.5: Significant part (or parts) of the task can be computerized-robotized (e.g., computer-supported tasks and navigation-adding technologies).

- Score 1: There is an existing technology or a technology under development at least at TRL3 that can be implemented for the execution of the task.

It is worth noting that tasks characterized by score 0.5 are subjected to task transformation and in some cases to human-machine collaborative tasks, while tasks with score 1 are mainly subjected to substitution.

It should be clarified that the selection of the three-tier score scale is arbitrary in the sense that any other discrete or continuous scale could be implemented. However, it is the scope of this work to elucidate the trends of the occupational transformation in agriculture and not to provide exact measures of the expected change. 
For each task of an occupation, a value, $\bar{a}_{i, j}, i \in O, j \in T$, is allocated representing the average outcome of the experts rating on the susceptibility of the specific task to automatization following the above-mentioned scale. Finally, the overall susceptibility rating of an occupation results as the weighted, in terms of the task importance, average value of the tasks it contains, that is:

$$
s_{i}=\sum_{j \in T} \overline{a_{i j}} \hat{w}_{i j}, \quad i \in O, j \in T
$$

\subsection{Consideration of Workforce and Wages in Agricultural Occupations}

For the purpose of having a comprehensive assessment of the agricultural occupations landscape in terms of the nature of the occupations and the impact of robotization on the agricultural employment, the above-presented results should be mapped to the budgetary and workforce data for the corresponding occupations. For this purpose, Figure 3 was built from data (data refer to May 2017) available by the U.S. Department of Labor statistics, representing the mean hourly wage and total work force distribution of the examined occupations.

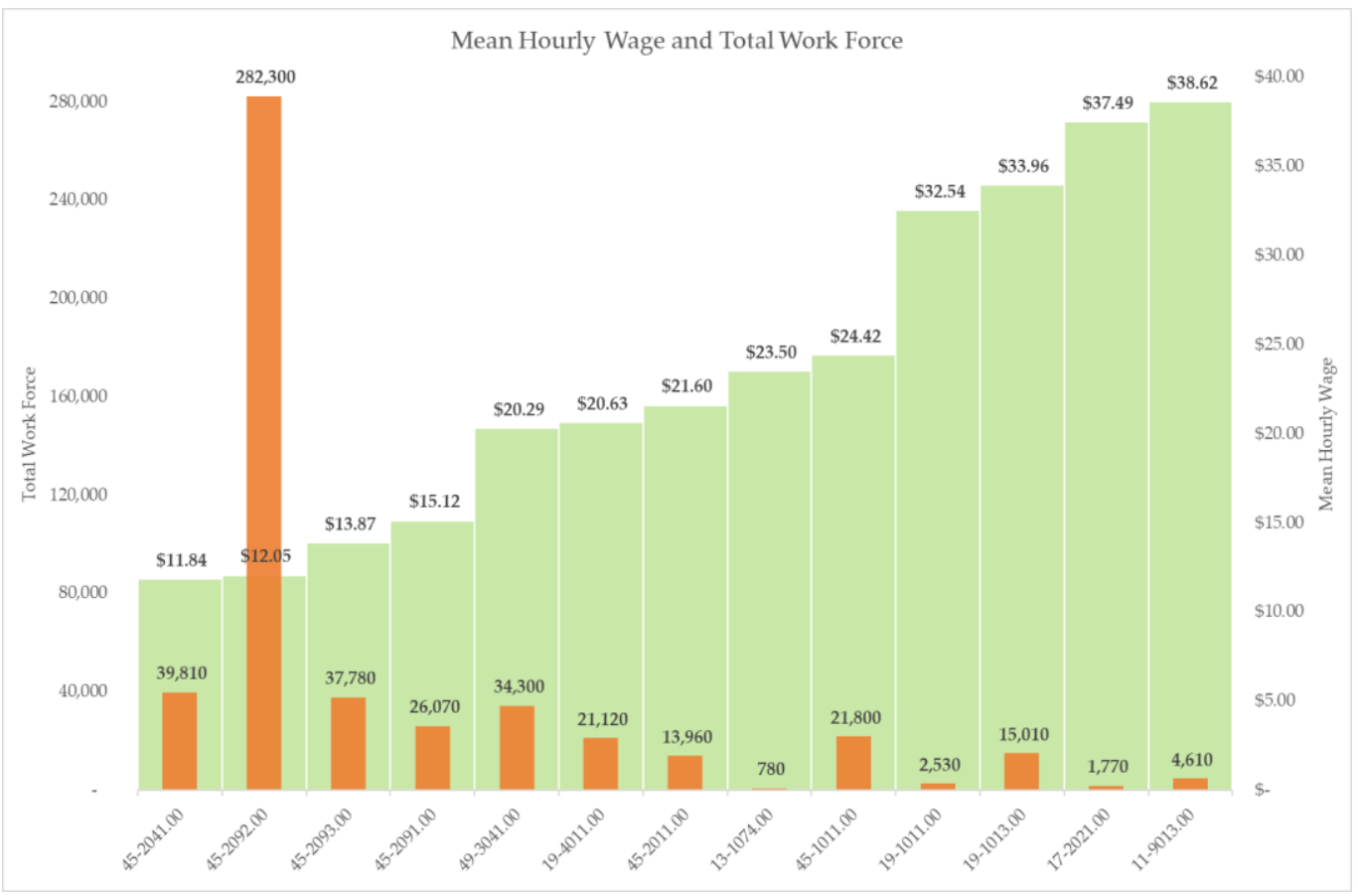

Figure 3. Total work force (blue bars) and mean hourly wage (grey bars) distribution of the agricultural occupations according to data from the U.S. Department of Labor (May 2017); correspondence between the occupations and codes: 119013.01: Nursery and Greenhouse Managers; 11-9013.02: Farm and Ranch Managers; 13-1074.00: Farm Labor Contractors; 172021.00: Agricultural Engineers; 19-1011.00: Animal Scientists; 19-1013.00: Soil and Plant Scientists; 19-4011.01: Agricultural Technicians; 19-4011.02: Food Science Technicians; 45-1011.07: First-Line Supervisors of Agricultural Crop and Horticultural Workers; 45-1011.08: First-Line Supervisors of Animal Husbandry and Animal Care Workers; 45-2011.00: Agricultural Inspectors; 45-2041.00: Graders and Sorters, Agricultural Products; 45-2091.00: Agricultural Equipment Operators; 452092.01: Nursery Workers; 45-2092.02: Farmworkers and Laborers; Crop, 45-2093.00: Farmworkers, Farm, Ranch; 49-3041.00: Farm Equipment Mechanics and Service Technicians.

\section{Results and Discussion}

\subsection{Occupation Mapping}

Based on the methodology described in Section 2.2, the 17 occupations that were identified in agricultural production domain were classified to cognitive routine, cognitive non-routine, manual routine, and manual non-routine. The detailed outcome of 
the classification (for each individual task of all selected occupations) is available at https:/ / ibo.certh.gr/open-datasets/, (accessed on 10 January 2021). In order to quantify this analysis, the calculated $l^{C-M}$ and $l^{R-m R}$ coefficients were mapped onto a Cartesian graph representing the ordinate and abscissa of the graph. The resulted graph is illustrated in Figure 4, with blue, green, orange, and yellow asterisks denoting (in conjunction to the colors of the four areas in Figure 1) the occupations belonging in the first, second, third, and fourth quadrant of the graph, respectively.

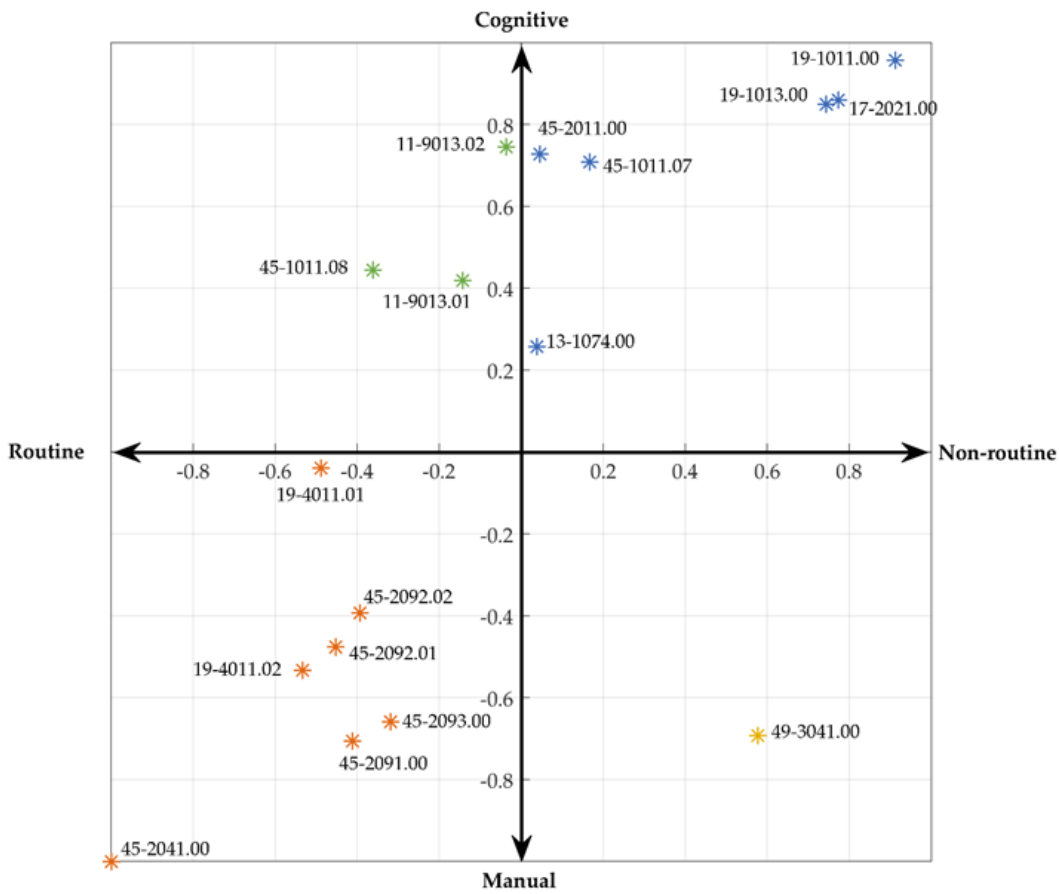

Figure 4. Mapping of agricultural occupations in terms assessed manual and cognitive levels as well as assessed routine and non-routine levels; correspondence between the occupations and codes: 11-9013.01: Nursery and Greenhouse Managers; 11-9013.02: Farm and Ranch Managers; 13-1074.00: Farm Labor Contractors; 17-2021.00: Agricultural Engineers; 19-1011.00: Animal Scientists; 191013.00: Soil and Plant Scientists; 19-4011.01: Agricultural Technicians; 19-4011.02: Food Science Technicians; 45-1011.07: First-Line Supervisors of Agricultural Crop and Horticultural Workers; 45-1011.08: First-Line Supervisors of Animal Husbandry and Animal Care Workers; 45-2011.00: Agricultural Inspectors; 45-2041.00: Graders and Sorters, Agricultural Products; 45-2091.00: Agricultural Equipment Operators; 45-2092.01: Nursery Workers; 45-2092.02: Farmworkers and Laborers, Crop; 45-2093.00: Farmworkers, Farm, Ranch; 49-3041.00: Farm Equipment Mechanics and Service Technicians.

In the framework of this analysis, the larger the positive values of $l^{R-m R}$ and $l^{C-M}$ (first quadrant of the graph-occupation of a non-routing cognitive nature), more skills are required for the occupation at hand to be performed in terms of education, perception, judgement, and experience. According to the present investigation, six occupations belong to this category, namely "animal scientists" (Code: 19-1011.00), "soil and plant scientists" (Code: 19-1013.00), "agricultural engineers" (Code: 17-2021.00), "first-line supervisors of agricultural crop and horticultural workers" (Code: 45-1011.07), "agricultural inspectors" (Code: 45-2011.00), and "farm labor contractors" (Code: 13-1074.00). According to the $\mathrm{O}^{*} \mathrm{Net}$ description, the execution of the tasks related to these occupations needs high expertise and a high level of education. More specifically, they are associated, for example, with conducting research in genetics, nutrition, growth, reproduction, and domestic farm animals' development ("animal scientists") as well as with examination of the composition of soils and decision making on the control of pests and management of plants, trees, and crops ("soil and plant scientists"). An occupation belonging in the 
first quadrant also requires knowledge of engineering to face with agricultural problems, such as agricultural products' processing, electrification, water and soil, and conservation ("agricultural engineers"). Additionally, the responsibilities also include coordinating and supervising the operations of workers ("first-line supervisors of agricultural crop and horticultural workers"), hiring seasonal workers ("farm labor contractors"), and inspection of agricultural commodities and thus ensuring quality, health, and safety ("agricultural inspectors").

In contrast, the closer the values of $l^{R-m R}$ and $l^{C-M}$ to -1 are, the lower the skills are that usually are required. As it can be seen from Figure 4, most of the agricultural occupations are in this quadrant (occupations of a routine manual nature). In ascending order of routine level, the agricultural occupations are classified as follows: "graders and sorters, agricultural products" (Code: 45-2041.00); "food science technicians" (Code: 19-4011.02); “agricultural technicians" (Code: 19-4011.01); "nursery workers" (Code: 45-2092.01); "agricultural equipment operators" (Code: 45-2091.00); "farmworkers and laborers, crop" (Code: 45-2092.02); and "farmworkers, farm, ranch" (Code: 45-2093.00). The aforementioned occupations deal with tasks such as grading and sorting ("graders and sorters, agricultural products"), performing standardised tests to find out the food properties ("food science technicians"), and collecting samples from animals or crops or recording data to help scientists ("agricultural technicians"). Furthermore, activities belonging in the third quadrant involve offering nursery facilities ("nursery workers"); operating equipment for planting, cultivating, and harvesting ("agricultural equipment operators"); and manual operations, including cultivation, harvesting, and repairing fences via using hand tools ("farmworkers and laborers, crop"). Finally, the activities may pertain to attending of farm animals ("farmworkers, farm, ranch").

Three occupations were found to be in the second quadrant (occupations of a routine cognitive nature), the tasks of which require cognitive abilities, however, occurring in a routine manner. The occupations, in a descending order of cognitive requirements are "farm and ranch managers" (Code: 11-9013.02), "first-line supervisors of animal husbandry and animal care workers" (Code: 45-1011.08), and "nursery and greenhouse managers" (Code: 11-9013.01). The tasks of these occupations refer to operations related to agricultural establishments; hiring and supervising workers during everyday agricultural activities ("farm and ranch managers"); and coordinating animal activities of animal-related activities, such as husbandry ("first-line supervisors of animal husbandry and animal care workers"). There also tasks referring to planning and coordinating the activities of workers in harvesting and cultivating horticultural specialties (nursery and greenhouse managers).

Finally, only one occupation was found to require manual operations in a non-routine manner, namely the "farm equipment mechanics and service technicians" (Code: 493041.00) occupation. This occupation involves activities such as diagnosis or repairing of farm machinery like tractors and irrigation systems.

\subsection{Rating Susceptibility to Robotization}

Based on the methodology described in Section 2.3, the rate of potential robotization for each one of the examined agricultural occupations are listed in Table 2.

In order to provide a visual connection between the rate of susceptibility to robotization and the nature of each occupation, the above-presented results were incorporated into the occupations nature map generated in the previous section. Figure 5 depicts the resultant graph, where three (colored) zones have been also introduced indicating the level of susceptibility. The "green zone" represents the characterization of a low level of susceptibility (rate between 0 and 0.33 ), the "yellow zone" represents a medium level of susceptibility (rate between 0.34 and 0.66), and the "red zone" represents a high level of susceptibility (rate between 0.67 and 1). Furthermore, the size of the cycles in Figure 5 is proportional to the rate of the occupation. 
Table 2. The potential adoption rate of robotization for the examined agricultural occupations.

\begin{tabular}{lcc}
\hline Occupation & Code & Rate \\
\hline Soil and Plant Scientists & $19-1013.00$ & 0.04 \\
Animal Scientists & $19-1011.00$ & 0.17 \\
First-Line Supervisors of Agricultural Crop and & $45-1011.07$ & 0.17 \\
Horticultural Workers & & 0.17 \\
First-Line Supervisors of Animal Husbandry and Animal & $45-1011.08$ & 0.19 \\
Care Workers & $19-4011.01$ & 0.23 \\
Agricultural Technicians & $17-2021.00$ & 0.23 \\
Agricultural Engineers & $49-3041.00$ & 0.32 \\
Farm Equipment Mechanics and Service Technicians & $13-1074.00$ & 0.34 \\
Farm Labor Contractors & $11-9013.02$ & 0.36 \\
Farm and Ranch Managers & $45-2011.00$ & 0.38 \\
Agricultural Inspectors & $19-4011.02$ & 0.42 \\
Food Science Technicians & $11-9013.01$ & 0.46 \\
Nursery and Greenhouse Managers & $45-2093.00$ & 0.67 \\
Farmworkers, Farm, Ranch & $45-2092.02$ & 0.71 \\
Farmworkers and Laborers, Crop & $45-2091.00$ & 0.74 \\
Agricultural Equipment Operators & $45-2092.01$ & 0.95 \\
Nursery Workers & $45-2041.00$ & \\
Graders and Sorters, Agricultural Products & & \\
\hline
\end{tabular}

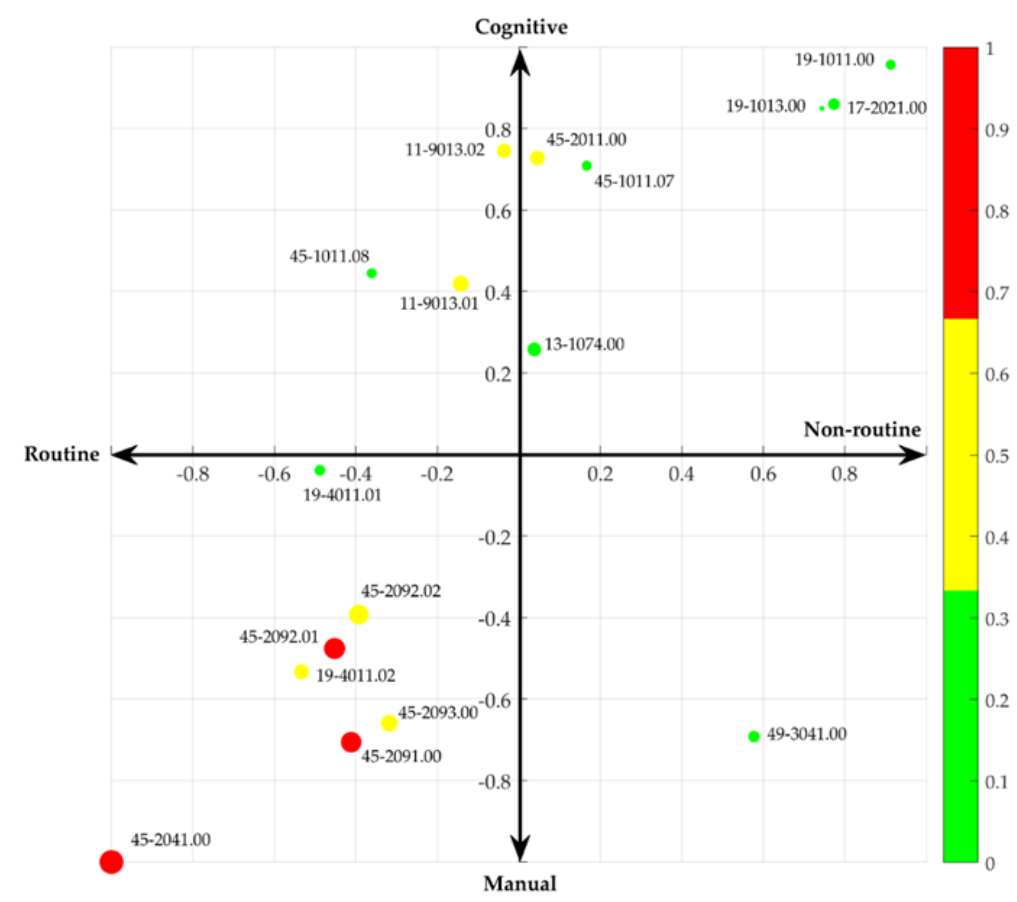

Figure 5. Mapping of the rate of susceptibility to robotization of agricultural occupations in conjunction to the assessed manual and cognitive levels as well as their routine and non-routine levels; correspondence between the occupations and codes: 11-9013.01: Nursery and Greenhouse Managers; 11-9013.02: Farm and Ranch Managers; 13-1074.00: Farm Labor Contractors; 17-2021.00: Agricultural Engineers; 19-1011.00: Animal Scientists; 19-1013.00: Soil and Plant Scientists; 19-4011.01: Agricultural Technicians; 19-4011.02: Food Science Technicians; 45-1011.07: First-Line Supervisors of Agricultural Crop and Horticultural Workers; 45-1011.08: First-Line Supervisors of Animal Husbandry and Animal Care Workers; 45-2011.00: Agricultural Inspectors; 45-2041.00: Graders and Sorters, Agricultural Products; 45-2091.00: Agricultural Equipment Operators; 45-2092.01: Nursery Workers; 45-2092.02: Farmworkers and Laborers, Crop; 45-2093.00: Farmworkers, Farm, Ranch; 49-3041.00: Farm Equipment Mechanics and Service Technicians. 
As expected, the occupations containing standardized tasks and being carried out manually are more likely to be substituted by robotics. Therefore, plausibly, "graders and sorters, agricultural products" (Code: 45-2041.00) appear to be most "at threat" of being robotized, following by "nursery workers" (Code: 45-2092.01) and "agricultural equipment operators" (Code: 45-2091.00). Similar kinds of occupations can be partially automated, such as "farmworkers, farm, ranch" (Code: 45-2093.00), "farmworkers and laborers, crop" (Code: 45-2092.02), and "food science technicians" (Code: 19.4011.02) but with a lower potential as compared with the three first occupations. There has already been a plethora of agricultural robots for carrying out the everyday and arduous operations that are included in the above occupations as mentioned in the introduction, leading to increased productivity. Remarkably, although belonging to a quadrant that nominally is very likely to be robotized, the occupation of "agricultural technicians" (Code: 19-4011.01) does not seem as if it can be automated so easily in the near-term future, mainly owing to the variability in the types of tasks it entails.

In the same vein as the manual routine tasks, although in a relatively lower extent, occupations requiring cognitive skills can also be computerized, especially those performed in a standardized way. A very low potential of automating its tasks was noticed for "first-line supervisors of animal husbandry and animal care workers" (Code: 45-1011.08). However, as can be seen from Figure 5, "farm and ranch managers" (Code: 11-9013.02) and "nursery and greenhouse managers" (Code: 11-9013.01) belong in this category. Typically, managers must make strategic decisions relying on data collection and analysis. Nevertheless, algorithms can also advance decisions by processing a broader set of data compared to those handled by an experienced manager. The result, however, will not be biased, thus resulting in robust decision making. Even a partial replacement of some tasks by computers or robots can constitute powerful tools allowing managers to control more employees and prioritize the time to tasks that require more attention.

Most non-routine occupations requiring cognitive skills represent that part of occupations that are almost untouched by the potential for robotization. This is attributed mainly to the distinguished abilities of humans, who are still unmatched regarding copying with volatile and changing environments like the agricultural one [33]. Based on the present analysis, the most difficult occupation to computerize and robotize occupation in the shortto mid-term future is "soil and plant scientists" (Code: 19-1013.00) since the right execution of its tasks demands versatile skills, high-level education, and experience. Correspondingly, other scientists, namely "animal scientists" (Code: 19-1011.00) and "agricultural engineers" (Code: 17-2021.00) as well as "first-line supervisors of agricultural crop and horticultural workers" (Code: 45-1011.07) and "farm labor contractors" (Code: 13-1074.00), are not susceptible to robotization. Out of the six identified occupations of the first quadrant, only one occupation, namely "agricultural inspectors" (Code: 45-2011.00), has the potential to be partially computerized. Finally, most of the tasks belonging to "farm equipment mechanics and service technicians" (Code: 49-3041.00) occupation, although they are performed manually, have less potential to be computerized because of the non-routine nature of the majority of these tasks

It should be noted that such a map that incorporates both the nature of an occupation and its corresponding susceptibility to robotization is actually a dynamic depiction, in the sense that any change in an occupation due to robotization will transform the entire occupation by entirely or partially removing tasks and also by generating new tasks with a different mix of cognitive-manual or routine-nonroutine skill requirements. This transformation can potentially trigger a different quadrant assignment to an occupation.

\subsection{Reflections of Robotization on Agricultural Occupations Landscape}

Based on the classification of the occupations relying on their nature as well as by considering the above-presented available data for the occupations' share in the total work force, it can be inferred that $88 \%$ of the workforce executes tasks of manual nature carried out either in a routine manner $(81 \%)$ or a non-routine one $(7 \%)$. Furthermore, cognitive 
skills requirements prevail with $12 \%$ of the total work force, whose tasks are performed either routinely $(3 \%)$ or non-routinely $(9 \%)$ (Figure 6a). The corresponding annual budget of agricultural-related occupations account for $69 \%$ (stemming from occupations of manual routine nature), $9 \%$ (stemming from occupations of manual non-routine nature), $6 \%$ (stemming from occupations of cognitive/routine nature), and 16\% (stemming from occupations of cognitive non-routine nature) (Figure 6b).

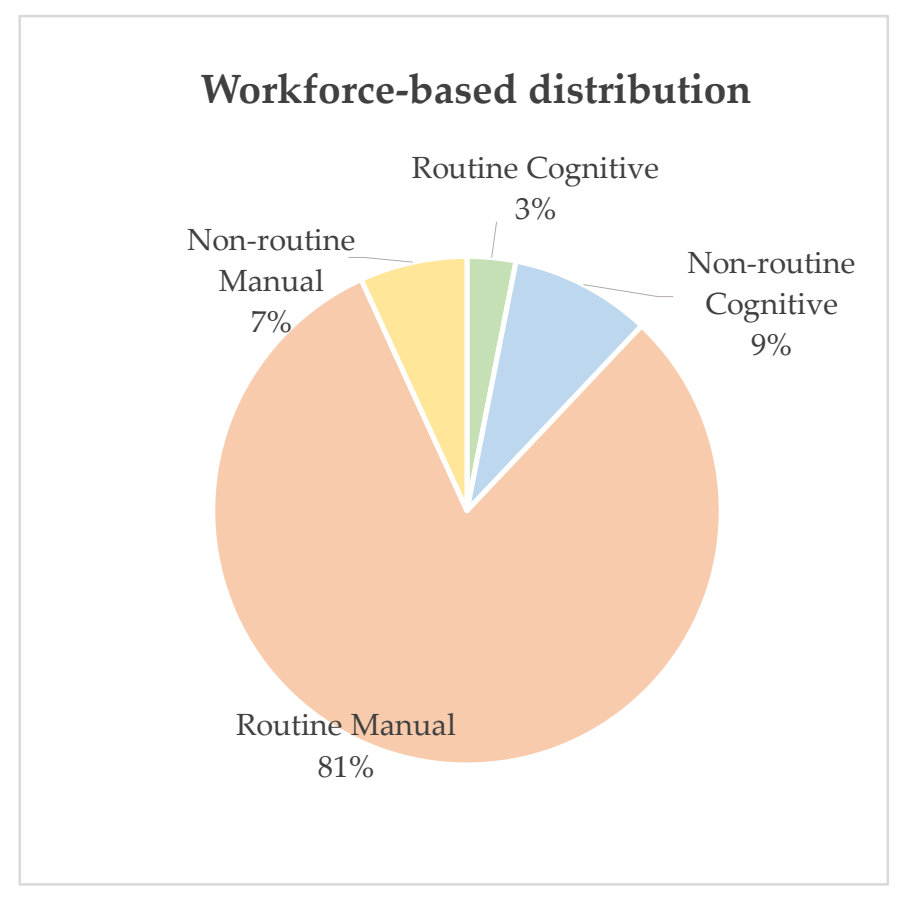

(a)

\section{Annual budget-based distribution}

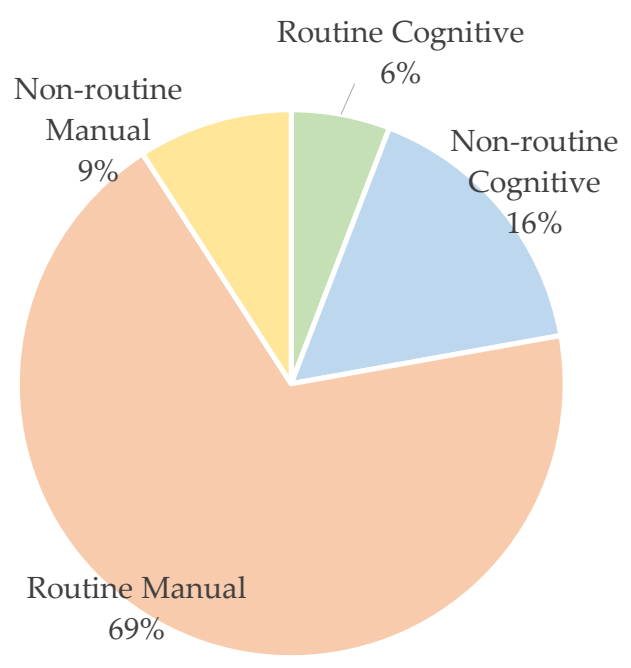

(b)

Figure 6. Workforce-based (a) and annual budget-based (b) distribution of the agricultural occupations.

Regarding the susceptibility to robotization, the distribution of the agricultural work force in occupations of low, medium, and high levels of automation potential is depicted in Figure $7 \mathrm{a}$. For almost $70 \%$ of the occupations, there is an existing technology or a technology under development at least at TRL3 that can be implemented for the execution of most of the tasks constitute this occupation. In terms of annual budget, this percentage corresponds to $56 \%$ of the total annual budget (Figure $7 \mathrm{~b}$ ). Moreover, $13 \%$ of agricultural workforce is employed in occupations that have medium possibility of being partially automated, while $17 \%$ of the total agricultural workforce is employed to occupations where there is not any reasonable indication, at the time being, that its prevailing tasks can be computerized-robotized in the short- to mid-term future. In terms of the annual budget, occupations under medium or low robotization potential account for $16 \%$ and $28 \%$, respectively, of the total annual budget of agricultural occupations. Based on work results and the above analysis, in absolute numbers, $70 \%$ of the workforce and $56 \%$ of the annual budget that correspond to occupations of a high susceptibility to robotization translate to approximately 350,000 workers whose jobs have a high probability of being replaced by robotization. Furthermore, this represent an outflux of approximately $\$ 8.8$ billion per year from agricultural occupations in the U.S. within the mid-term future. 
Workforce-based distribution

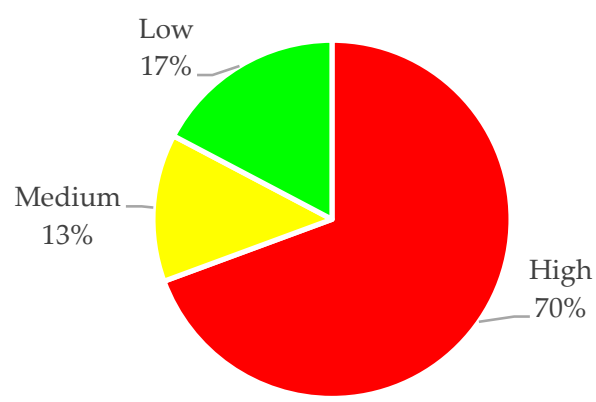

(a)
Annual budget-based distribution

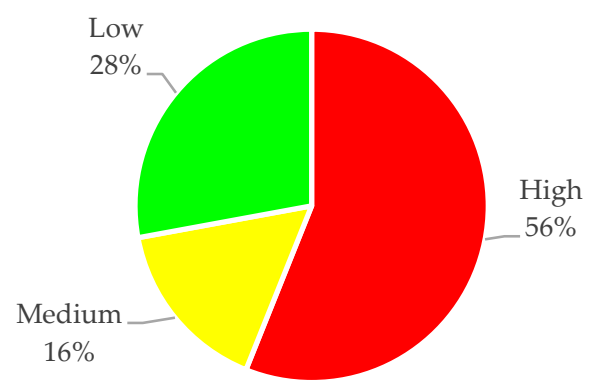

(b)

Figure 7. Workforce-based (a) and annual budget-based (b) distribution of the agricultural occupations in terms of their susceptibility to robotization.

The above presented results on the effect of robotization on the agricultural work force and annual budget should, however, be understood as a "static" prediction in the sense that the prediction process implemented here does not takes into consideration the dynamic nature of a job transformation as also explained previously. Even if certain tasks are automated, there will be still tasks within the occupation that require a human being. Additionally, automated tasks always generate labor requirements either in the form of low skills (for the execution of the so-called work residuals) or in the form of high skills (system control and intervention). To that effect, further research is required for capturing this dynamic process and this generates several issues for future research.

\section{Conclusions}

In the present work, 17 agricultural occupations were reviewed and characterized in relation to the nature each individual task they entail and mapped to a two-dimensional space representing the manual versus cognitive nature and the routine versus non-routine nature of an occupation. Subsequently, the potential for robotization was assessed, mapped against each task individually, and resulted in a weighted average adoption rate for each one of the agricultural occupations.

The largest part of the existing work force is employed in occupations with tasks being characterized as manual and performed mainly in a routine manner rather $(81 \%$ of the agricultural work force is engaged in these occupations) than in a non-routine manner (with 7\% of the agricultural work force being engaged in these occupations). It is well known and has been seen in other production domains that the manual execution of an occupation in conjunction with a standardized task design is the key factor to determine a high susceptibility to robotization. This fact is depicted in agricultural occupations by the results that $70 \%$ of the work force that is "threatened" by computerization is engaged in occupations where the tasks is of the manual/routine nature. Moreover, within this segment, occupations subjected to a partial automation were also identified along with one for which no reasonable indication exists that the tasks it contains can be computerizedrobotized in the short future (i.e., "agricultural technicians"). In contrast, non-standardized tasks reduce this potential even for a manual nature of the occupation (e.g., the rate of susceptibility potential for "farm equipment mechanics and service technicians" was found to be 0.23$)$.

On the contrary, cognitive skills are required only for a small number of workers that are also better paid, namely $3 \%$ of the work force is engaged in occupations of a cognitive routine nature, while $9 \%$ of the work force is engaged in occupations of a cognitive nonroutine nature. In brief, the former occupations have a potential to be partly robotized, while the latter correspond to a low rate of susceptibility to robotization. This evidence shows that in agricultural occupations, contrary to paradigms seen in other production 
domains, the replacement of cognitive skills through robotization still has a long way to go. This is because, at present, human abilities of perception, reasoning, and response are still difficult to be imitated in the multiple-parametric environment of agricultural operations despite the relative progress in the field of AI.

In conclusion, the objective of this study was to provide insights into the transformation process of agricultural occupations towards robotization. It is shown that several repetitive and exhausting jobs will be disrupted by automation and new, more challenging jobs that call for higher qualifications will be created, while others will be complemented by robotics. Silhouetting the expected transformation represents an effort for a subsequent identification of social threats, in terms of unemployment, and job and wages polarization, among others, but also of opportunities in terms of emerged skills and training requirements. Technical foresights on the evolution of the occupational landscape transition ensures for a better prepared society in view of this unavoidable change and a social, sustainable development of agricultural domain.

Author Contributions: Conceptualization, V.M. and D.B.; methodology, V.M., D.B., S.P. and C.G.S.; validation, M.L. and D.K.; formal analysis, D.B. and C.G.S.; investigation, V.M.; resources, C.G.S. and D.B.; data curation, M.L. and D.K.; writing—original draft preparation, V.M. and D.B.; writingreview and editing, S.P., C.G.S. and D.B.; visualization, M.L. and D.K.; supervision, D.B. All authors have read and agreed to the published version of the manuscript.

Funding: This research received no external funding.

Institutional Review Board Statement: Not applicable.

Informed Consent Statement: Not applicable.

Data Availability Statement: The data presented in this study are available in https:/ /ibo.certh.gr / open-datasets / (accessed on 10 January 2021).

Conflicts of Interest: The authors declare no conflict of interest.

\section{References}

1. Bechar, A.; Vigneault, C. Agricultural robots for field operations: Concepts and components. Biosyst. Eng. 2016, 149, 94-111. [CrossRef]

2. Eizicovits, D.; Berman, S. Efficient sensory-grounded grasp pose quality mapping for gripper design and online grasp planning. Rob. Auton. Syst. 2014, 62, 1208-1219. [CrossRef]

3. Lampridi, M.; Kateris, D.; Sørensen, C.G.; Bochtis, D. Energy footprint of mechanized agricultural operations. Energies 2020, 13, 769. [CrossRef]

4. Benos, L.; Tsaopoulos, D.; Bochtis, D. A review on ergonomics in agriculture. part I: Manual operations. Appl. Sci. 2020, 10, 1905. [CrossRef]

5. Bechar, A.; Vigneault, C. Agricultural robots for field operations. Part 2: Operations and systems. Biosyst. Eng. 2017, 153, 110-128. [CrossRef]

6. Hayashi, S.; Shigematsu, K.; Yamamoto, S.; Kobayashi, K.; Kohno, Y.; Kamata, J.; Kurita, M. Evaluation of a strawberry-harvesting robot in a field test. Biosyst. Eng. 2010, 105, 160-171. [CrossRef]

7. Xiong, Y.; Peng, C.; Grimstad, L.; From, P.J.; Isler, V. Development and field evaluation of a strawberry harvesting robot with a cable-driven gripper. Comput. Electron. Agric. 2019, 157, 392-402. [CrossRef]

8. Søgaard, H.T.; Lund, I. Application Accuracy of a Machine Vision-controlled Robotic Micro-dosing System. Biosyst. Eng. 2007, 96, 315-322. [CrossRef]

9. Gonzalez-de-Soto, M.; Emmi, L.; Perez-Ruiz, M.; Aguera, J.; Gonzalez-de-Santos, P. Autonomous systems for precise sprayingEvaluation of a robotised patch sprayer. Biosyst. Eng. 2016, 146, 165-182. [CrossRef]

10. Haibo, L.; Shuliang, D.; Zunmin, L.; Chuijie, Y. Study and Experiment on a Wheat Precision Seeding Robot. J. Robot. 2015, 2015. [CrossRef]

11. Ruangurai, P.; Ekpanyapong, M.; Pruetong, C.; Watewai, T. Maejo International Journal of Science and Technology Automated three-wheel rice seeding robot operating in dry paddy fields. Maejo Int. J. Sci. Technol. 2015, 9, 403-412. [CrossRef]

12. Bochtis, D.D.; Sørensen, C.G.; Jørgensen, R.N.; Nørremark, M.; Hameed, I.A.; Swain, K.C. Robotic weed monitoring. Acta Agric. Scand. Sect. B Soil Plant Sci. 2011, 61, 202-208. [CrossRef]

13. Utstumo, T.; Urdal, F.; Brevik, A.; Dørum, J.; Netland, J.; Overskeid, Ø.; Berge, T.W.; Gravdahl, J.T. Robotic in-row weed control in vegetables. Comput. Electron. Agric. 2018, 154, 36-45. [CrossRef] 
14. Fountas, S.; Mylonas, N.; Malounas, I.; Rodias, E.; Hellmann Santos, C.; Pekkeriet, E. Agricultural Robotics for Field Operations. Sensors 2020, 20, 2672. [CrossRef]

15. Moysiadis, V.; Tsolakis, N.; Katikaridis, D.; Sørensen, C.G.; Pearson, S.; Bochtis, D. Mobile robotics in agricultural operations: A narrative review on planning aspects. Appl. Sci. 2020, 10, 3453. [CrossRef]

16. Shamshiri, R.R.; Weltzien, C.; Hameed, I.A.; Yule, I.J.; Grift, T.E.; Balasundram, S.K.; Pitonakova, L.; Ahmad, D.; Chowdhary, G Research and development in agricultural robotics: A perspective of digital farming. Int. J. Agric. Biol. Eng. 2018. [CrossRef]

17. Autor, D.H.; Levy, F.; Murnane, R.J. The skill content of recent technological change: An empirical exploration. Q. J. Econ. 2003, 118, 1279-1333. [CrossRef]

18. Nevavuori, P.; Narra, N.; Lipping, T. Crop yield prediction with deep convolutional neural networks. Comput. Electron. Agric. 2019, 163, 104859. [CrossRef]

19. Gutiérrez, S.; Diago, M.P.; Fernández-Novales, J.; Tardaguila, J. Vineyard water status assessment using on-the-go thermal imaging and machine learning. PLoS ONE 2018, 13, e0192037. [CrossRef] [PubMed]

20. Anagnostis, A.; Asiminari, G.; Papageorgiou, E.; Bochtis, D. A convolutional neural networks based method for anthracnose infected walnut tree leaves identification. Appl. Sci. 2020, 10, 469. [CrossRef]

21. Gao, J.; Liao, W.; Nuyttens, D.; Lootens, P.; Vangeyte, J.; Pižurica, A.; He, Y.; Pieters, J.G. Fusion of pixel and object-based features for weed mapping using unmanned aerial vehicle imagery. Int. J. Appl. Earth Obs. Geoinf. 2018, 67, 43-53. [CrossRef]

22. Vasconez, J.P.; Kantor, G.A.; Auat Cheein, F.A. Human-robot interaction in agriculture: A survey and current challenges. Biosyst. Eng. 2019, 179, 35-48. [CrossRef]

23. Adamides, G.; Katsanos, C.; Constantinou, I.; Christou, G.; Xenos, M.; Hadzilacos, T.; Edan, Y. Design and development of a semi-autonomous agricultural vineyard sprayer: Human-robot interaction aspects. J. F. Robot. 2017, 34, 1407-1426. [CrossRef]

24. Bechar, A.; Edan, Y. Human-robot collaboration for improved target recognition of agricultural robots. Ind. Robot Int. J. 2003, 30, 432-436. [CrossRef]

25. Bergerman, M.; Maeta, S.M.; Zhang, J.; Freitas, G.M.; Hamner, B.; Singh, S.; Kantor, G. Robot farmers: Autonomous orchard vehicles help tree fruit production. IEEE Robot. Autom. Mag. 2015, 22, 54-63. [CrossRef]

26. Liakos, K.; Busato, P.; Moshou, D.; Pearson, S.; Bochtis, D.; Liakos, K.G.; Busato, P.; Moshou, D.; Pearson, S.; Bochtis, D. Machine Learning in Agriculture: A Review. Sensors 2018, 18, 2674. [CrossRef] [PubMed]

27. Benos, L.; Tagarakis, A.C.; Dolias, G.; Berruto, R.; Kateris, D.; Bochtis, D. Machine learning in agriculture: A comprehensive updated review. Sensors 2021, 21, 3758. [CrossRef]

28. Marinoudi, V.; Sørensen, C.G.; Pearson, S.; Bochtis, D. Robotics and labour in agriculture. A context consideration. Biosyst. Eng. 2019, 184, 111-121. [CrossRef]

29. United States Bureau of Labor Statistics. Standard Occupational Classification. 2018. Available online: https://www.bls.gov/soc/ (accessed on 10 January 2021).

30. O*NET Online. Preferences of Work Environments and Outcomes. 2020. Available online: https://www.onetonline.org/find/ descriptor/browse/Interests (accessed on 10 January 2021).

31. Bochtis, D.; Benos, L.; Lampridi, M.; Marinoudi, V.; Pearson, S.; Sørensen, C.G. Agricultural workforce crisis in light of the COVID-19 pandemic. Sustainability 2020, 12, 8212. [CrossRef]

32. Frey, C.B.; Osborne, M.A. The future of employment: How susceptible are jobs to computerisation? Technol. Forecast. Soc. Chang. 2017, 114, 254-280. [CrossRef]

33. Tervo, K.; Koivo, H.N. Adaptation of the human-machine interface to the human skill and dynamic characteristics. In Proceedings of the 19th World Congress, The International Federation of Automation Control, Cape Town, South Africa, 24-29 August 2014; Volume 47, pp. 3539-3544. 